\title{
Detection and sizing of myocardial ischemia and infarction by nuclear magnetic resonance imaging in the canine heart
}

\author{
Andrew J. Buda, M.D., Alex M. Aisen, M.D., Jack E. Juni, M.D., \\ Kim P. Gallagher, Ph.D., and Rainer J. Zotz, M.D. \\ Ann Arbor, Mich.
}

The recent development of proton nuclear magnetic resonance (NMR) imaging provides a potential noninvasive method to assess myocardial ischemia and infarction. Previous studies have demonstrated that NMR can detect and localize acute infarction in animal models and in man without the necessity of paramagnetic contrast enhancement. ${ }^{1-3}$ This is based on the ability of NMR to characterize regional myocardial edema, which results from acute ischemic injury. ${ }^{1}$ However, there have been limited data reported addressing the ability of NMR imaging to size infarction, and concerning the sensitivity of magnetic relaxation times to differentiate between ischemic and infarcted tissue. Accordingly, the purpose of our study was twofold: first, to assess the ability of proton NMR imaging to size the hypoperfused, at-risk myocardium and infarcted myocardium; and second, to evaluate the ability of $T_{1}$ and $T_{2}$ relaxation times to distinguish among normal, hypoperfused, and infarcted myocardium.

\section{METHODOLOGY}

Sixteen adult mongrel dogs of either sex, weighing 15 to $20 \mathrm{~kg}$, were anesthetized with intravenous pentobarbital $(30 \mathrm{mg} / \mathrm{kg}$ ) and ventilated artificially with room air delivered by a Harvard respirator via an endotracheal tube. A thoracotomy was performed in the fifth intercostal space, the lungs were

From the Cardiology Division, Department of Internal Medicine, and Departments of Radiology, Surgery, and Physiology, University of Michigan Medical School.

This work was supported, in part, by a Grant-in-Aid from the American Heart Association of Michigan and by Grant HL29716 from the National, Heart, Lung, and Blood Institute, National Institutes of Health, Bethesda, Md. Dr. Gallagher is the recipient. of NIH Research Career Development. Award K04 HL04120.

Received for publication July 8, 1985; accepted Aug. 12, 1985.

Reprint requests: Andrew J. Buda, M.D., Cardiology Division, University of Michigan Hospitals, 1405 E. Ann St., Ann Arbor, MI 48109. retracted, and the heart was supported in a pericardial cradle. Polyvinyl catheters were placed in the left internal jugular vein for fluid and drug administration, in the left atrium for injection of radioactive microspheres for subsequent autoradiography, and in the left carotid artery for blood pressure recording. A segment of the left circumflex coronary artery was dissected free proximal to the first major obtuse marginal branch, and a hydraulic occluder was placed around it.

All of the dogs underwent occlusion of the proximal circumflex artery. In three dogs, the mean occlusion time was $4.3 \pm 1.2$ hours (range 3 to 5 hours) without reperfusion. Ten dogs underwent $2.3 \pm 1.6$ hours occlusion (range 1 to 3 hours) with $2 \pm 0.6$ hours of reperfusion (range 2 to 2.5 hours). Three dogs underwent occlusion, but because of occluder failure in two and no ischemic changes seen by ECG and two-dimensional echocardiography (2DE) in one, these three animals served as sham controls. In all dogs, at 1 hour following occlusion, approximately 400,000 to 600,000 albumin microspheres labelled with technetium-99m were injected into the left atrium for subsequent autoradiography. ${ }^{4}$ Following death, the hearts were immediately excised and transported to our NMR imaging facility. In all cases, NMR imaging was performed within 15 minutes of killing the animal.

Nuclear magnetic resonance imaging. NMR imaging was performed with a system based on a 0.35 tesla superconducting magnet (Diasonics MTS/S Magnetic Resonance Scanner). For imaging, each excised heart was centered in a $30 \mathrm{~cm}$ diameter radiofrequency coil, and an external marker was used to identify the NMR level for subsequent pathologic sectioning. Images were acquired using a multi-slice acquisition, with a dual-spin echo pulse sequence. Five contiguous slices were collected with 


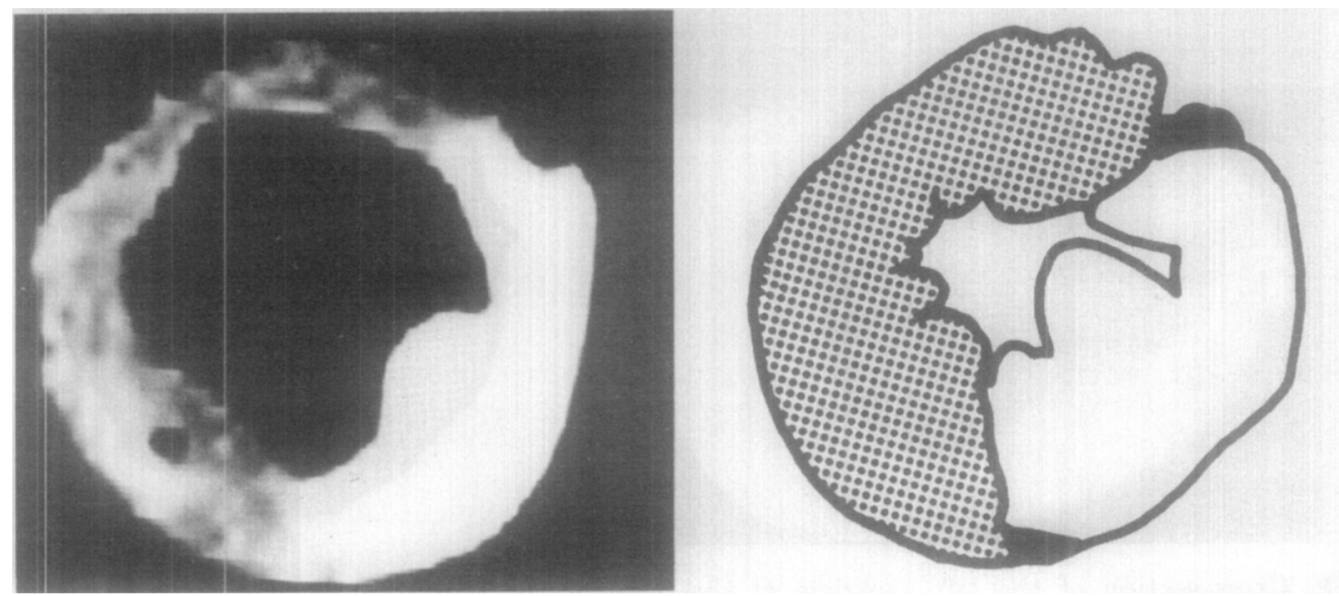

Fig. 1. Cross-section of the left ventricle at the level of the papillary muscles comparing NMR image (left panel) to schematic of pathologic findings (right panel) for the corresponding ring of tissue. This animal underwent 5-hour occlusion without reperfusion. The NMR abnormality corresponds well with the area of infarction (in white). In the schematic, the solid black area corresponds to myocardium at-risk determined by autoradiography and the stippled area represents normal myocardium.

a repetition rate (TR) of 0.5 second and echo-delays (TE) of 28 and 56 msec. Ten contiguous slices with the same center point were then acquired without retuning the apparatus, with a TR of 1.0 second and the same TEs. Pixel size was $1.7 \times 1.7 \mathrm{~mm}$, slice thickness was $7 \mathrm{~mm}$, and center-to-center spacing of the contiguous slices was $1.0 \mathrm{~cm}$. Using this protocol, four slices were acquired at each applied contiguous level through the center of the hearts with different TR-TE combinations. From these data, $T_{1}$ and $T_{2}$ relaxation times were computed for selected regions of interest. The computation program employed is furnished with the imager and assumes the intensity of a given pixel is approximated by the equation $\mathrm{I}=\mathrm{H}\left(\mathrm{I}-\exp \mathrm{TR} / \mathrm{T}_{1}\right) \exp \left(-\mathrm{TE} / \mathrm{T}_{2}\right)$, where $\mathrm{H}$ is a function of imager settings in the proton density, TE and TR are the pulse intervals employed, and $T_{1}$ and $\mathrm{T}_{2}$ are the tissue relaxation times. Image reconstructions were performed with a two-dimensional Fourier transform algorithm.

Pathologic analysis. Following imaging, the hearts were cooled in a freezer for approximately 30 minutes and were sliced into $5 \mathrm{~mm}$ transverse sections perpendicular to the long axis of the heart. An external marker was used to represent the pathologic slice corresponding to the NMR image. The heart slices were incubated in a $1 \%$ solution of 2, 3, 5-triphenyltetrazolium chloride (TTC) in phosphate buffer for 15 minutes at $37^{\circ} \mathrm{C}$. Incubation in TTC stains myocardium containing dehydrogenase enzymes (i.e., noninfarcted myocardium) red; infarcted myocardium remains unstained. ${ }^{5}$ All slices were weighed and the margins of the infarct were traced on a clear acetate overlay. The infarct area was measured by planimeter and was expressed as a percentage of the total slice area.

The in-vivo area-at-risk determination was performed by exposing the $5 \mathrm{~mm}$ slices of the left ventricle for 18 hours on an $8 \times 10$ inch sheet of high-speed $\mathrm{x}$-ray film, which was developed on an $\mathrm{X}$-omat automatic processor (Eastman Kodak Co., Rochester, N.Y.). Normally perfused tissue appeared as an area of high radiographic density on the final autoradiogram, whereas hypoperfused tissue appeared as an area of lower or absent radioactivity. ${ }^{4}$ All slices were traced, and the endocardial and epicardial margins were traced on clear acetate overlay. By superimposing the tracing over the autoradiogram, the boundary of the hypoperfused area was drawn at the edge of the zone of decreased radiographic density by visual assessment.

NMR image analysis. The image corresponding to the external marker was used for subsequent analysis and comparison to the same pathologic slice. Both first and second echo images were viewed, and the image demonstrating the most apparent abnormality was used for further analysis. This generally corresponded to the image with a TE of $56 \mathrm{msec}$ and a TR of 1.0 second. The analysis was first performed without any knowledge of the pathologic data. The NMR abnormality was measured by planimeter and was expressed as a percent of the total left ventricular slice area. Following this, the pathologic data were used to define regions of interest corresponding to the infarcted, at-risk but noninfarcted, and normal myocardium. From these regions of interest, 

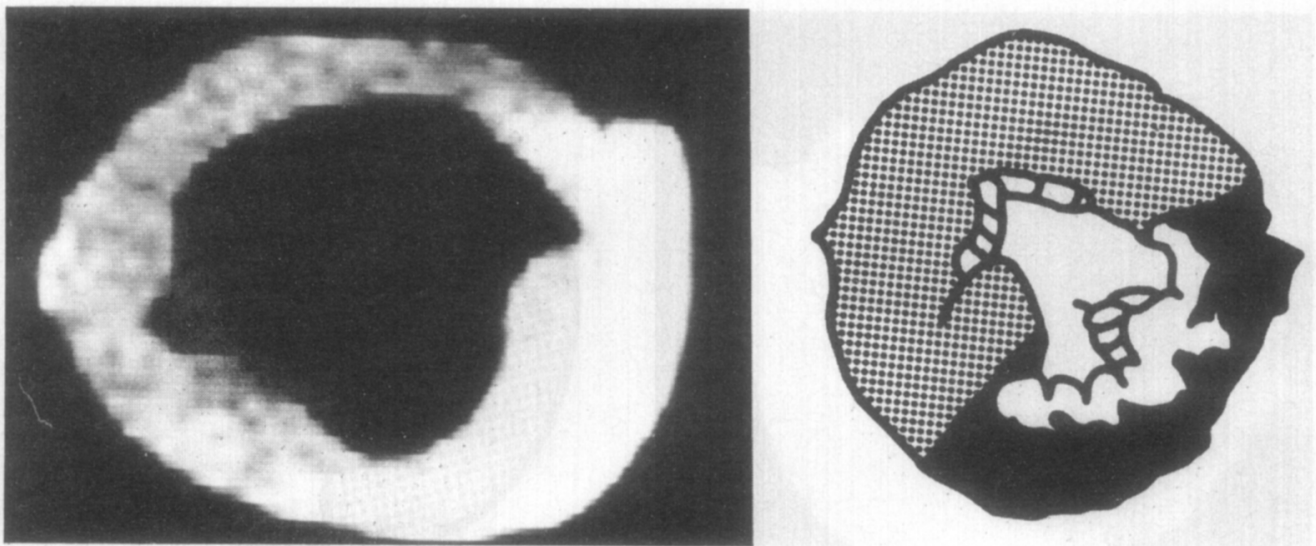

Fig. 2. Cross-section of the left ventricle at the level of the papillary muscles in an animal which underwent 1 hour of occlusion and 2 hours of reperfusion. The NMR abnormality (left panel) is larger than the area of infarction (in white, right panel) and corresponds better with the myocardium at-risk (solid black).

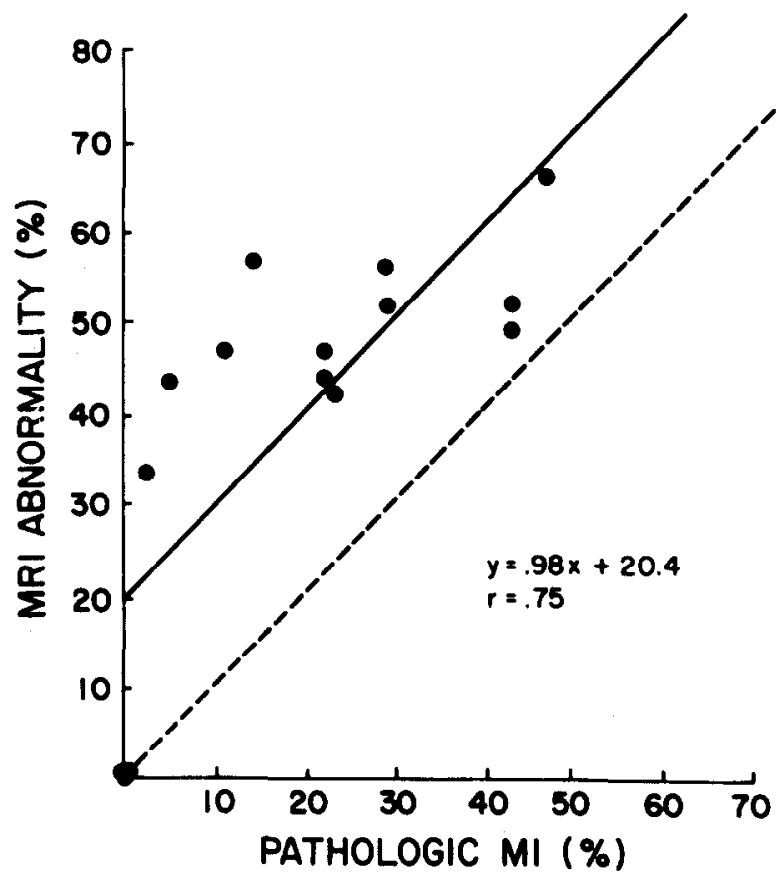

Fig. 3. Relationship between the pathologic myocardial infarction and the MRI abnormality. The line of identity is indicated by the dashed line. $\mathrm{MI}=$ myocardial infarction; $\mathrm{MRI}=$ magnetic resonance imaging.

both $T_{1}$ and $T_{2}$ relaxation times were then calculated.

Statistical analysis. All data are expressed as a mean \pm standard deviation of the mean. The relationship between NMR abnormality and at-risk, or infarcted, myocardium was performed using the least-squares fit for linear regression. ${ }^{6}$ Differences in the mean values for $T_{1}$ and $T_{2}$ between infarcted, ischemic, and normal myocardium were compared for statistical significance using the paired $t$ test.

\section{OBSERVATIONS}

In the 13 animals that underwent coronary occlusion, there was a distinct abnormality on the NMR image in the region of the posterior papillary muscle, corresponding to the left circumflex coronary artery distribution. In animals with a large infarct which included most of the at-risk zone, there was generally a good correspondence between the NMR abnormality and actual infarct size (Fig. 1). However, in animals with a smaller, nontransmural infarction, NMR imaging clearly overestimated the infarct size, but corresponded well to the hypoperfused, at-risk myocardium (Fig. 2). The data for all of the animals are summarized in Fig. 3 and 4. There was a good correlation $(r=0.95)$ between the NMR abnormality and the hypoperfused zone. However, the correlation between the NMR abnormality and infarct size was less good $(r=0.75)$, and there was a significant overestimation of actual infarct size, particularly in animals with smaller or nontransmural infarcts (Fig. 5). The NMR abnormality measured $40 \pm 22 \%$, whereas the pathologic hypoperfused, at-risk myocardium was $29 \pm 18 \%(p=\mathrm{NS})$, and the pathologic infarct size was $19 \pm 17 \%(p<0.005)$.

The $T_{1}$ and $T_{2}$ magnetic relaxation times are summarized in Table $I$ and Figs. 6 and 7. The $T_{1}$ relaxation time was $594 \pm 60 \mathrm{msec}$ in the normal myocardium, and was significantly increased in the ischemic $(715 \pm 67 \mathrm{msec}, p<0.0005)$ and infarcted regions $(752 \pm 106 \mathrm{msec}, p<0.0005)$. However, there was no significant difference between the $T_{1}$ relaxation times in the ischemic and infarcted zones. The $\mathrm{T}_{2}$ relaxation time in the normal myocardium was $39 \pm 3 \mathrm{msec}$, and was significantly increased in both the ischemic myocardium $(47 \pm 4 \mathrm{msec}$, 


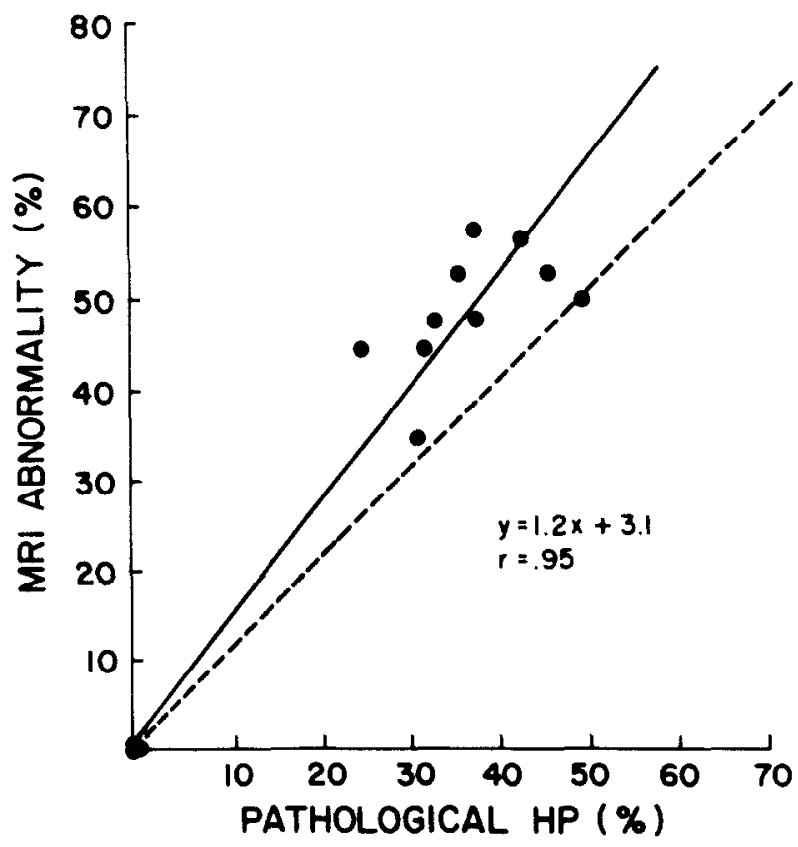

Fig. 4. Relationship between the pathologic hypoperfused myocardium at-risk and the MRI abnormality. The line of identity is indicated by the dashed line. $H P=$ hypoperfused; $M R I=$ magnetic resonance imaging.

$p<0.0005)$ and infarcted tissue $(49 \pm 4$ msec, $p<0.0005)$. Again, there was no significant difference between the $T_{2}$ relaxation time in the ischemic and infarcted zones.

\section{COMMENTS}

NMR characterizes proton density, found primarily in water in a variety of chemical forms, in the intact animal. In the setting of acute myocardial ischemic injury, the resulting NMR abnormality represents regional myocardial edema. Impaired cell volume regulation, interstitial fluid accumulation, and focal structural defects in the cell membrane integrity are early manifestations of ischemic injury. ${ }^{7-9}$ With necrosis, there is disruption of cell membranes and a loss of intracellular edema. This edema correlates with the extent of eventual myocardial cell necrosis, but remaining viable cells may also demonstrate persistent cell swelling. ${ }^{9}$ Willerson et al. ${ }^{7}$ demonstrated that myocardial edema can occur as early as $\mathbf{4 0}$ minutes after coronary occlusion, and is associated with a significant reduction in sodium-potassium-ATPase activity in the ischemic region, which probably contributes to the cell swelling. During a period of ischemia, the sodium-potassium-ATPase pump is unable to actively extrude sodium from the interior of cells, and this results in intracellular movement of sodium, chloride, and water with subsequent cell swelling. Coronary reflow

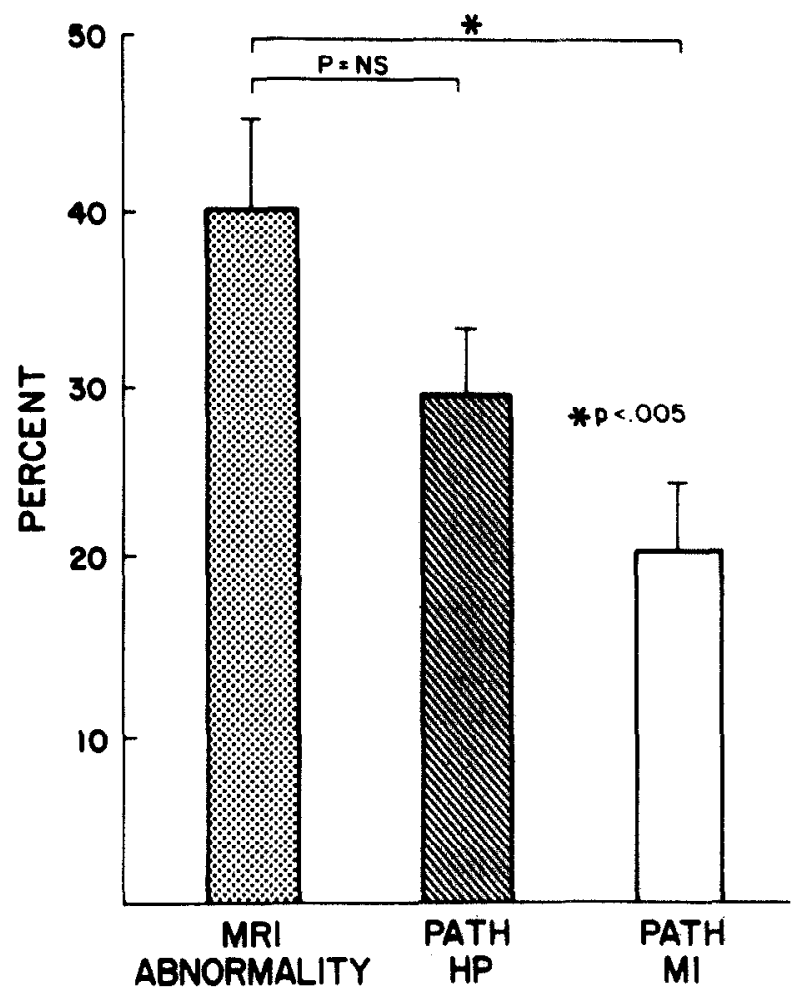

Fig. 5. Comparison of the size of the MRI abnormality with the pathologic hypoperfused myocardium at-risk and with the pathologic infarct area. The MRI abnormality was significantly greater than the infarct zone, but not significantly greater than the hypoperfused region. $H P=$ hypoperfused; $M I=$ myocardial infarct; $M R I=$ magnetic resonance imaging; $P A T H=$ pathologic.

after temporary occlusion tends to augment these fluid and electrolyte abnormalities. ${ }^{10}$

Our data indicate that NMR imaging can detect and localize myocardial edema related to myocardial ischemic injury, and our findings thus agree with previous reports..$^{1-3}$ However, in our excised canine model, the NMR abnormality significantly overestimated actual infarct size and corresponded better to the hypoperfused, at-risk myocardium. This suggests that myocardial edema extends outside the actual infarct region to include regions of jeopardized myocardium. Since most of our animals underwent reperfusion, the significance of this finding is particularly relevant in terms of coronary reperfusion.

Previous studies have demonstrated increased left ventricular wall thickness on coronary reperfusion. ${ }^{11-13}$ The tissue edema noted on NMR probably contributes to this increased wall thickness. Furthermore, it is possible that this regional tissue edema contributes to both the diastolic ${ }^{14}$ and systolic ${ }^{15-18}$ left ventricular functional abnormalities which occur following coronary reperfusion, and to 


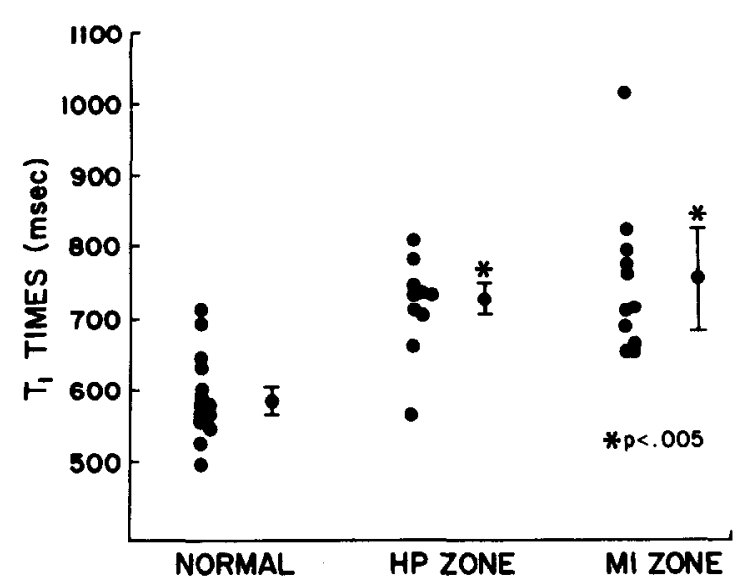

Fig. 6. $T_{1}$ relaxation times for normal myocardium, the hypoperfused zone, and the infarct region. $T_{1}$ times in both hypoperfused and myocardial infarct zones were significantly prolonged. $H P=$ hypoperfused; $M I=$ myocardial infarction.

Table I. Magnetic relaxation times

\begin{tabular}{|c|c|c|c|c|c|}
\hline \multicolumn{2}{|c|}{$\begin{array}{c}\text { Normal } \\
\text { myocardium }\end{array}$} & \multicolumn{2}{|c|}{$\begin{array}{l}\text { Hypoperfused } \\
\text { myocardium }\end{array}$} & \multicolumn{2}{|c|}{$\begin{array}{c}\text { Infarcted } \\
\text { myocardium }\end{array}$} \\
\hline $\begin{array}{c}T_{1} \\
\text { (msec) }\end{array}$ & $\begin{array}{c}T_{2} \\
\text { (msec) }\end{array}$ & $\begin{array}{c}T_{1} \\
(m s e c)\end{array}$ & $\begin{array}{c}T_{2} \\
\text { (msec) }\end{array}$ & $\begin{array}{c}T_{1} \\
\text { (msec) }\end{array}$ & $\begin{array}{c}T_{2} \\
(\mathrm{msec})\end{array}$ \\
\hline $594 \pm 60$ & $39 \pm 3$ & $5 \pm 67^{*}$ & $47 \pm 4^{*}$ & $752 \pm 106^{*}$ & $49 \pm$ \\
\hline
\end{tabular}

Mean $\pm \mathrm{SD}$.

${ }^{*} p<0.0005$ vs corresponding time in normal myocardium.

the delay in functional recovery. Whether the regional myocardial edema noted on NMR produces local compressive forces which may further influence blood flow in ischemia is unknown. It is conceivable that this regional edema may limit myocardial reperfusion and contribute to the "no-reflow" phenomenon, ${ }^{19,20}$ which is known to occur following coronary reflow. It has been demonstrated in the kidney $^{21}$ and the brain ${ }^{22,23}$ that prolonged ischemia results in intracellular swelling that can compress adjacent capillaries, thus providing a mechanism for perpetuation of the ischemic process. In this regard, previous investigators ${ }^{9,24-26}$ have demonstrated that hypertonic mannitol may reduce myocardial injury, increase coronary blood flow, and improve ventricular function during acute myocardial ischemia, both in anesthetized and in conscious animal models. However, the precise mechanism by which mannitol reduces infarct size is uncertain, since it affects both coronary vascular resistance and cell swelling, and is an oxygen-free radical scavenger. ${ }^{27}$

Another important feature of NMR is its ability

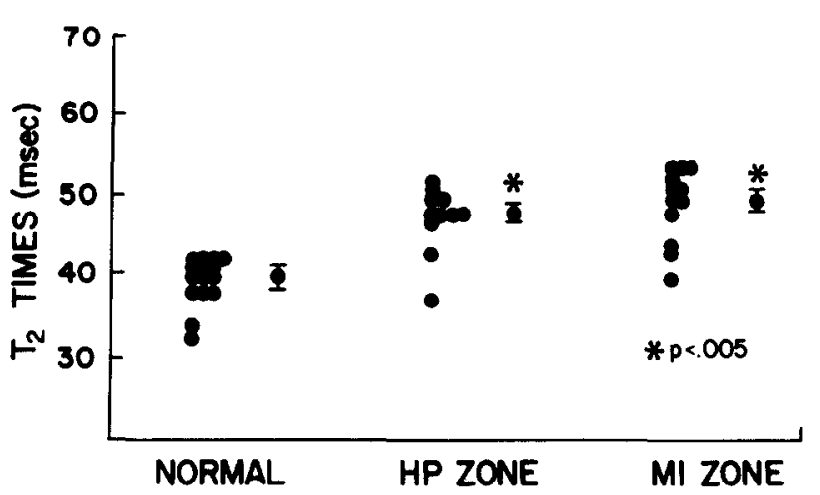

Fig. 7. $\mathrm{T}_{2}$ relaxation times for normal myocardium, the hypoperfused zone, and the infarct region. $T_{z}$ times in both hypoperfused and myocardial infarct zones were significantly prolonged. $H P=$ hypoperfused; $M I=$ myocardial infarct.

to characterize tissues by magnetic relaxation times. Higgins et al. ${ }^{1}$ demonstrated in excised canine hearts a significant increase in $T_{2}$ relaxation time, but no difference in $T_{1}$ times in infarcted regions compared to remote normal myocardium. This increase in $\mathrm{T}_{2}$ time correlated linearly to local water content. Johnston et al. ${ }^{28}$ found increases in both $T_{1}$ and $T_{2}$ relaxation times after 3 hours of coronary artery occlusion, which tended to be accentuated by reperfusion. Our results concur with those of Johnson et al., in that both $T_{1}$ and $T_{2}$ times were increased in both ischemic and infarcted tissues, compared to normal myocardium. The discrepancy related to $T_{1}$ time may be due to differences in experimental protocols. Most of our animals and those of Johnston et al. underwent coronary reperfusion after 1 to 3 hours of coronary occlusion, unlike those of Higgins et al., ${ }^{1}$ which underwent 24-hour occlusion without reperfusion. Additional studies comparing nonreperfused to reperfused occlusion models will be necessary to further examine $T_{1}$ and $T_{2}$ relaxation time differences that may be related to reperfusion.

There was no difference between $T_{1}$ and $T_{2}$ relaxation times in ischemic or infarcted zones in our study. This suggests that NMR may be unable to distinguish between ischemic and infarcted tissue without the use of a paramagnetic contrast agent. However, NMR clearly demonstrated $T_{1}$ and $T_{2}$ relaxation time prolongations in the hypoperfused region-at-risk, which included the infarcted myocardium.

Our results apply only to the excised, nonbeating, canine heart. There may be significant differences in NMR abnormalities and $T_{1}$ and $T_{2}$ relaxation times 
in the in vivo situation. Wesbey et al..$^{3}$ studied seven dogs by ECG gated NMR imaging in vivo at 2 to 7 days after coronary ligation. In the infarcted animals, signal intensity was increased in the region corresponding to infarction, with prolongation of the $\mathrm{T}_{2}$ relaxation time compared with normal myocardium. Pflugfelder et al. ${ }^{29}$ examined 15 dogs before, and serially up to 6 hours after, coronary artery ligation in vivo by gated NMR imaging. Increased signal intensity was noted in the ischemic myocardium by 4 hours after coronary occlusion. In both of these studies, however, there was no attempt made to size the ischemic or infarcted tissue. The sizing of ischemic and infarcted myocardium in the in vivo beating heart may be more difficult because of motion-related image degradation, but the experience of these investigators ${ }^{3,29}$ and our own early experience, suggests that if may be feasible, since respiratory gating and more rapid acquisition of NMR images further improves image quality. Nevertheless, our results indicate that NMR imaging is useful in the assessment of acute ischemic injury in an animal model, and provide promise for the clinical assessment and sizing of jeopardized, at-risk myocardium in the setting of acute myocardial infarction.

\section{SUMMARY}

The usefulness of NMR imaging to size infarcted and hypoperfused, ischemic myocardium was assessed in 16 dogs which underwent coronary artery occlusion and reperfusion. During occlusion, technetium-99 microspheres were injected into the left atrium. Following death, the hearts were excised and underwent NMR imaging with a 0.35 tesla magnet, using multiple spin-echo pulse sequences. The epicardium of the heart was marked to indicate the level of the NMR cross-sectional tomographic image. The heart was subsequently breadloafed into $5 \mathrm{~mm}$ sections and the corresponding NMR crosssection was flagged for analysis. Autoradiography was performed to measure the hypoperfused, at-risk zone, and triphenyltetrazolium chloride staining was used to measure infarct size. For the flagged tomographic slice, the size of the NMR abnormality correlated well $(r=0.95)$, and was comparable to the actual hypoperfused, at-risk zone of the left ventricle. However, NMR estimates of infarct size correlated less well $(r=0.75)$ with the pathologic measure, and significantly overestimated actual infarct size $(p<0.005)$. The $T_{1}$ and $T_{2}$ values were consistently increased $(p<0.0005)$ in both the hypoperfused and infarct zones, compared to normal myo- cardium. We conclude that NMR imgaging can detect acute myocardial ischemia and infarction, but overestimates infarct size and corresponds better to the area of hypoperfused, ischemic myocardium. In this excised canine heart occlusion-reperfusion model, the NMR abnormality corresponded best to the area including both infarction and the surrounding ischemic region.

We gratefully acknowledge the excellent technical assistance of Mila Turla and Diane Pace in the completion of this study. We thank Mrs. Sharon Haglund and Ms. Sheree Wilson for preparing the manuscript.

\section{REFERENCES}

1. Higgins CB, Herfkens R, Lipton MJ, Sievers R, Sheldon P, Kaufman L, Crooks LE: Nuclear magnetic resonance imaging of acute myocardial infarction in dogs: Alterations in magnetic relaxation times. Am J Cardiol 52:184, 1983.

2. Higgins CB, Lanzer P, Stark D, Botvinick E, Schiller NB, Crooks L, Kaufman L, Lipton MJ: Imaging by nuclear magnetic resonance in patients with chronic ischemic heart disease. Circulation 69:523, 1984.

3. Weshey G, Higgins CB, Lanzer P, Botvinick E, Lipton MJ: Imaging and characterization of acute myocardial infarction in vivo by gated nuclear magnetic resonance. Circulation 69:125, 1984

4. DeBoer LWV, Strauss HW, Kloner RA, Kule RE, Davis RF, Maroko PR, Braunwald E: Autoradiographic method for measuring the ischemic myocardium at risk: Effects of verapamil on infarct size after experimental coronary artery occlusion. Proc Natl Acad Sci 77:6119, 1980.

5. Fishbein MC, Meerbaum S, Rit .J, Lando U, Kanmatsuse K, Mercier JC, Corday E, Ganz W: Early phase acute myocardial infarct size quantification: Validation of the triphenyltetrazolium chloride tissue enzyme staining ter hnique. AM HraRT J 101:59:3, 1981

6. Steel RGD, Torne JH: Principles and procedures of statistics. New York, 1960, McGraw-Hill Book. Cis, Inc pp 99.131, 161-193, 332

7. Willerson JT, Scales F, Mukherjee A, Platt M, Templeton, G, Fink B, Buja M: Abnormal myocardial fluid retention as an early manifestation of ischemic injury. Am .J Pathol 87:159, 1977 .

8. Jennings RB, Sommers HM, Kaltenbach IP, West J.J: Electrolyte alterations in acute myocardial ischemic injury. Circ Res 14:260, 1964.

9. Powell WJ Jr, DiBona DR, Flores J, Leaf A: The protective effect of hyperosmotic mannitol in myocardial ischemia and necrosis. Circulation 54:608, 1976.

10. Whalen DA, Hamilton MB, Ganote CE, Jennings RB: Effect of a transient period of ischemia on myocardial cells. $\mathrm{I}$. Effects on cell valume regulation. Am I Pathol 74:381, 1974.

11. Gaasch WH, Bernard SA: The effect of acute changes in coronary blood flow on left ventricular end-diastolic wall thickness: An echocardiographic study. Circulation 56:593, 1977.

12. Heyndrickx GR, Baig H, Nellens P, Lensen I, Fishbein MC, Vatner SF: Depression of regional blood flow and wall thickening after brief coronary occlusion. Am J Physiol 234(suppl 6): H653, 1978.

13. Haendchen RV, Corday E, Torres M, Maurer G, Fishbein MC, Meerbaum S: Increased regional end-diastolic wall thickness early after reperfusion: A sign of irreversibly damaged myocardium. J Am Coll Cardiol 3:1444, 1984.

14. Tilton GD, Bush LR, Apprill PG, Buja LM, Willerson JT: Effect of diltiazem and propranolol on left ventricular seg- 
mental relaxation during temporary coronary arterial occlusion and one month reperfusion in conscious dogs. Circulation 71:165, 1985 .

15. Braunwald E, Kloner RA: The stunned myocardium: Prolonged post ischemic ventricular dysfunction. Circulation 66:1146, 1982.

16. Ellis SE, Henschke CI, Sandor T, Wynne J, Braunwald E, Kloner RA: Time course of functional and biochemical recovery of myocardium salvaged by reperfusion. J Am Coll Cardiol 1:1047, 1983.

17. Lavallee M, Cox D, Patrick TA, Vatner SF: Salvage of myocardial function by coronary artery reperfusion 1,2 , and 3 hours after occlusion in conscious dogs. Circ Res 53:235, 1983.

18. Bush LR, Buja LM, Samowitz W, Rude RE, Watnen M, Tilton GD, Willerson JT: Recovery of left ventricular segmental function after long-term reperfusion following temporary coronary occlusion in conscious dogs. Comparison of 2and 4-hour occlusion. Circ Res 53:248, 1983.

19. Kloner RA, Ganote CE, Jennings RB: The "no reflow" phenomenon after temporary coronary occlusion in the dog. $\mathrm{J}$ Clin Invest 54:1496, 1974.

20. Willerson IT, Watson .JT, Hutton I, Templeton GH, Fixler DE: Reduced myocardial reflow and increased coronary vascular resistance following prolonged myocardial ischemia in the dog. Circ Res 36:771, 1975.

21. Flores J, DiBona RD, Beck $\mathrm{CH}$, Leaf A: The role of cell swelling in ischemic renal damage and the protective effect of hypertonic solute. J Clin Invest 51:118, 1972.

22. Chiang J, Kowada DM, Ames A III, Wright RL, Majno G:
Cerebral ischemia. III. Vascular changes. Am $J$ Pathol 52:455, 1968.

23. Cantu RC, Ames A III: Experimental prevention of cerebral vasculature obstruction produced by ischemia. J Neurosurg 30:50, 1969.

24. Willerson JT, Powell WJ Jr, Guinery TE, Stark JJ, Sanders CA, Leaf A: Improvement in myocardial function and coronary blood flow in ischemic myocardium after mannitol. $\mathrm{J}$ Clin Invest 51:2989, 1972.

25. Willerson JT, Watson JT, Hutton I, Fixler DE, Curry GC, Templeton GH: The influence of hypertonic mannitol on regional myocardial blood flow during acute and chronic myocardial ischemia in anesthetized and awake intact dogs. J Clin Invest 55:892, 1975.

26. Kloner RA, Reimer KA, Willerson JT, Jennings RB: Reduction of experimental infarct size with hyperosmolar mannitol. Proc Soc Exp Biol Med 151:667, 1976.

27. Stewart JR, Blackwell WH, Conte SL, Loughlin V, Hess ML, Greenfield LJ: Prevention of myocardial ischemia/reperfusion injury with oxygen free-radical scavengers. Surg Forum 33:317, 1982.

28. Johnston DL, Brady TJ, Ratner AV, Rosen BR, Newell JB, Pohost GM, Okada RD: Assessment of myocardial ischemia with proton magnetic resonance: Effects of a three hour coronary occlusion with and without reperfusion. Circulation 71:595, 1985.

29. Pflugfelder PW, Wisenberg G, Prato FS, Carroll SE, Turner KL: Early detection of canine myocardial infarction by magnetic resonance imaging in vivo. Circulation 71:587, 1985. 